\title{
Mathematical modeling of the melting of ice under conditions of motion of a heat drill
}

\author{
Ekaterina Zakharova ${ }^{1, *}$, and Mikhal Purin ${ }^{1}$ \\ ${ }^{1}$ National Research Tomsk Polytechnic University, 634050 Tomsk, Russia
}

\begin{abstract}
The mathematical modeling results of the simultaneous processes of heat and mass transfer under the conditions of intense phase changes (melting of ice) during the movement of cryobot have been given. The spatial unevenness of the melting rate of ice has been taken into account. It has been established that the rate of passage of the cryobot depends essentially on its temperature. According to the results of the numerical simulation, considerable cooling of the cryobot sheath has been established. The latter is due to the high endothermic effect of melting ice.
\end{abstract}

\section{Introduction}

One of the more effective ways of studying the structure, the material composition and the dynamics of ice deposits is drilling wells. The main aim of deep drilling was initially to obtain continuous ice-core samples. Its study allows getting the most complete information about the gas composition, the degree of its dustiness and the temperature fluctuations of our planet for the last 900 thousand years [1].

When drilling ice, like any breed, there are problems. As is known, under the influence of gravity the glaciers are in a stressed state. The walls of the well become unstable due to deformation of the ice.[2] There is a narrowing of the well, which in the future can lead to accidents. To prevent this situation, the well is filled with a special fluid that compensates for the pressure of the ice. Recently, during drilling, a mixture of a hydrocarbon liquid is used that is similar to kerosene with difluoroethane. The mixture at low temperatures (up to -60 ${ }^{\circ} \mathrm{C}$ ) maintains fluidity, and its density is close to the density of ice. The main disadvantage is the toxicity for living microorganisms. As a consequence, the samples taken can be contaminated [3].

This process can be carried out in three ways: the first variant involves the thermal destruction of ice structures [4]; the second variant involves the use of mechanical action on the layers of ice ("classical" drilling) [5]; the third variant is based on the combined chemical and thermal effects [6].

The third way is to use a melting probe. Its movement is carried out by heating the ice to the formation of melt water. Water flows around the cryobat and freezes behind it, while the cryobot itself continues to move under the influence of gravity. The use of cryobot avoids the previously described problems, since a mine is not created for its operation, and the impact on ice occurs only at the expense of high temperature [7]. Energy costs for its

*Corresponding author: eaz15@tpu.ru 
use are relatively small. However, like any method, there are drawbacks: low penetration rate and the need for a liquid phase [5]. The representative of this method is the cryobot specialized probe-robot of deep-glacial penetration - cryobot.

In the summer of 2001, the cryobot was tested on the Longyear Glacier, where a well of 23 meters deep was drilled without complications [8]. At the current stage of the development of science and technology, this depth is maximal. Most likely, this is due to the poor knowledge of the processes of melting and crystallization of massive ice structures by a local source of heating. This is due to the fact that a phase transition front is formed in the melting process, which is characterized by the presence of a powerful and singularly concentrated heat sink, as well as by a jumplike change in the thermophysical characteristics of ice upon passage through it. In addition, it should be noted that the shape of this phase transition is not substantially linear and depends on the divergent distribution of heat fluxes in the ice, respectively, we can say that the processes of phase transformations during the melting of ice are actual unresolved problems of modern physics.

The aim of this work is the mathematical modeling of heat transfer processes that occur together under ice melting conditions during the movement of the cryobot.

\section{Physical statement}

At a time $\mathrm{t}=0$, the heat flux is acts by a limited region of ice. Ice heats up and melts. A heterogeneous structure is formed, consisting of a solid and a liquid phase of water $[9,10]$. In solving the problem, ice has been assumed to be homogeneous. At the initial time, the temperature of the entire volume of ice has been assumed to be the same.

\section{Mathematical statement}

The equation for "the ice-water" system has the following form $[7,11,12]$ :

$$
\frac{\mathrm{C} \cdot \mathrm{P}}{\mathrm{Fo}} \cdot \frac{\partial \theta}{\partial \tau}+\mathrm{U} \cdot \mathrm{Pe} \frac{\partial \theta}{\partial \mathrm{X}}+\mathrm{V} \cdot \operatorname{Pe} \frac{\partial \theta}{\partial \mathrm{Y}}=\operatorname{div}(\Lambda \cdot \operatorname{grad} \theta) \mp \mathrm{Pom}_{\text {melt }} .
$$

where Fo - the Fourier's criterion; Pe - the Peclet's criterion; $\theta$ - dimensionless temperature; $\Lambda$ - dimensionless thermal conductivity; $\mathrm{Pom}_{\text {melt }}-$ Pomerantsev's criterion; $\mathrm{U}, \mathrm{V}-$ dimensionless water velocities; $\mathrm{C}=\mathrm{c} / \mathrm{c}_{0}, \mathrm{P}=\rho / \rho_{0}, \Lambda=\lambda / \lambda_{0}, \theta=\mathrm{T} / \mathrm{T}_{0} ; \mathrm{X}=\mathrm{x} / \mathrm{l}, \mathrm{Y}=\mathrm{y} / 1$ dimensionless heat capacity, density, coefficient of thermal conductivity, temperature and dimensionless steps in area; $\mathrm{c}_{0}, \rho_{0}, \lambda_{0}, \mathrm{~T}_{0}, 1$ - parameters of dimensionization.

The Pomerantsev's criterion:

$$
\mathrm{Pom}_{\mathrm{melt}}=\frac{\mathrm{Q} \cdot \mathrm{W} \cdot \mathrm{l}_{0}^{2}}{\mathrm{~h} \cdot \lambda_{0} \cdot \mathrm{T}_{0}}
$$

where $\mathrm{Q}$ - melting heat of ice, $\mathrm{J} / \mathrm{kg} ; \mathrm{W}$ - melting rate, $\mathrm{m} / \mathrm{s} ; \mathrm{h}-$ step in area, $\mathrm{m} ; \mathrm{T}_{0}-$ temperature, $\mathrm{K}$.

To solve this equation, the following assumptions are made:

1. The water that forms during melting has a very thin layer that "sticks" to the cryobot and ice. Accordingly, the speed of water movement is not taken into account;

2. The temperature field of the ice at the initial instant of time is homogeneous;

3. Heat transfer from the $\mathrm{Z}$ coordinate is not taken into account.

For the convenience of analyzing the information obtained, the calculations were carried out in dimensionless quantities. The basic equation "the ice-water" system is the energy equation [12]: 


$$
\frac{\mathrm{C} \cdot \mathrm{P}}{\mathrm{Fo}} \cdot \frac{\partial \theta}{\partial \tau}=\frac{\partial}{\partial \mathrm{X}}\left(\Lambda \frac{\partial \theta}{\partial \mathrm{X}}\right)+\frac{\partial}{\partial \mathrm{Y}}\left(\Lambda \frac{\partial \theta}{\partial \mathrm{Y}}\right) \mp \mathrm{Pom}_{\mathrm{melt}} \cdot
$$

The equation energy for cryobot:

$$
\frac{\mathrm{C}_{\mathrm{c}} \cdot \mathrm{P}_{\mathrm{c}}}{\mathrm{Fo}} \frac{\partial \theta}{\partial \tau}=\Lambda_{\mathrm{c}}\left(\frac{\partial^{2} \theta}{\partial \mathrm{X}^{2}}+\frac{\partial^{2} \theta}{\partial \mathrm{Y}^{2}}\right)+\mathrm{Pom}_{\mathrm{tv}}
$$

where $\mathrm{C}_{\mathrm{c}}, \mathrm{P}_{\mathrm{c}}, \Lambda_{\mathrm{c}}-$ dimensionless heat capacity, density and coefficient of thermal conductivity of cryobot; Pom $\mathrm{tv}_{\mathrm{t}}$ - Pomerantsev's criterion of thermal emission. [12] The mathematical statement also includes the corresponding boundary conditions:

$$
\begin{gathered}
\mathrm{x}=0 \quad 0<y<\mathrm{H} \frac{\partial \theta}{\partial \mathrm{x}}=0, \mathrm{t}>0 ; \mathrm{y}=\mathrm{l} 0<y<\mathrm{H} \frac{\partial \theta}{\partial \mathrm{x}}=0, \mathrm{t}>0 \\
\mathrm{y}=0 \quad 0<\mathrm{x}<\mathrm{l} \frac{\partial \theta}{\partial \mathrm{Y}}=0, \mathrm{t}>0 ; \mathrm{y}=\mathrm{H} 0<\mathrm{x}<\mathrm{x}_{1} \Lambda_{\text {ice }} \frac{\partial \theta}{\partial \mathrm{X}}=\Lambda_{\text {air }} \frac{\partial \theta}{\partial \mathrm{X}} \\
\mathrm{y}=\mathrm{H} \mathrm{x}_{2}<x<l \Lambda_{\text {ice }} \frac{\partial \theta}{\partial \mathrm{x}}=\Lambda_{\text {air }} \frac{\partial \theta}{\partial \mathrm{x}} \mathrm{H}<y<\mathrm{H}_{1} \mathrm{x}=\mathrm{x}_{2} \Lambda_{\mathrm{c}} \frac{\partial \theta}{\partial \mathrm{x}}=\Lambda_{\text {air }} \frac{\partial \theta}{\partial \mathrm{x}}+\mathrm{Ki} \\
\mathrm{H}<y<\mathrm{H}_{1} \mathrm{x}=\mathrm{x}_{1} \Lambda_{\mathrm{c}} \frac{\partial \theta}{\partial \mathrm{x}}=\Lambda_{\text {air }} \frac{\partial \theta}{\partial \mathrm{x}}+\mathrm{Ki} ; \mathrm{H}<y<\mathrm{H}_{1} \mathrm{x}=\mathrm{x}_{2} \Lambda_{\mathrm{c}} \frac{\partial \theta}{\partial \mathrm{x}}=\Lambda_{\text {air }} \frac{\partial \theta}{\partial \mathrm{x}}+\mathrm{Ki}
\end{gathered}
$$

where $\mathrm{Ki}$ - criterion of Kirpichev [13].

\section{The results}

According to the results of the mathematical modeling of cryobot movement, the formation of a vertical shaft with even edges has been established.

Fig. 1 "a" and 1"b" show the temperature fields in the "cryobot-ice-air" system the moment of immersion of the cryobot at depth $1 \mathrm{~m}$. It can be noted that ice heats up slightly and temperature gradients are present only in the region near the device. A nonlinear fusion front is formed, the shape of which is equidistant to the shape of the cryobot. Analysis of Fig. 2 "a" and 1 "b" shows that an increase temperature in cryobot by $50 \mathrm{~K}$ (from $450 \mathrm{~K}$ to 500 $\mathrm{K})$ leads to the fact that at the same time the average bulk cryobot temperature at the initial temperature $\mathrm{T}=450 \mathrm{~K}$ is substantially lower than the cryobot temperature at the initial value $\mathrm{T}=500$.

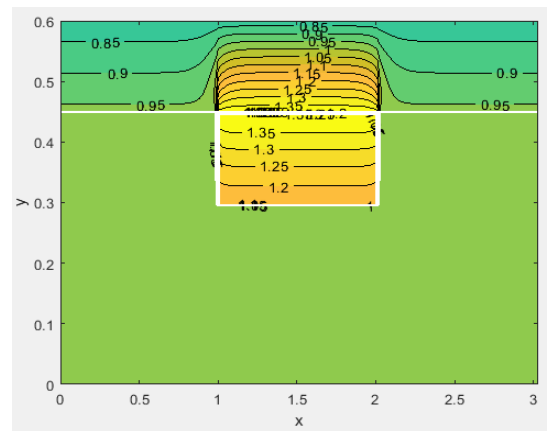

(a)

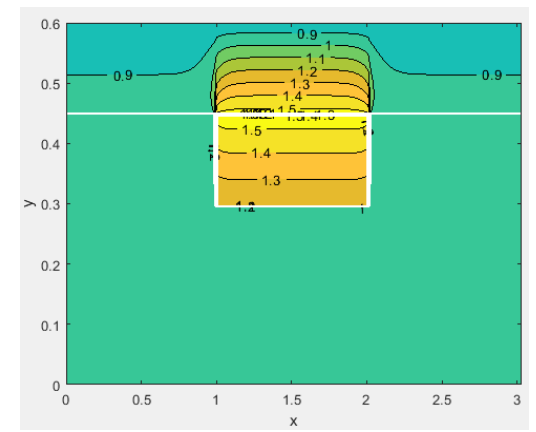

(b)

Fig. 1. (a) The temperature field in the "ice-cryobot-air" system with a temperature of the last $450 \mathrm{~K}$. (b) The temperature field in the "ice-cryobot" system at a temperature of $500 \mathrm{~K}$. 
Fig. 2 "a" and 2 "b" show the tempature fields at the moment of the cryoblot sinking at various initial ice temperatures. The temperature of the ice varied in the range $263 \mathrm{~K}-253 \mathrm{~K}$. It can be noted that when the temperature of the ice decreases by $10 \mathrm{~K}$ (from 263 to 253), the degree of cooling of the cryobot does not increase. So the average volume temperature of the cryobot has practically not changed. At the same time, practically identical temperature gradients are formed in the cryobote. This is due to the fact that when the cryobot moves in the region of conjugation of the walls of the heat drill and ice, a water membrane is formed, the temperature of which is equal to the phase transition temperature of $273 \mathrm{~K}$. Therefore, the cooling degree of the cryobot remains practically unchanged.

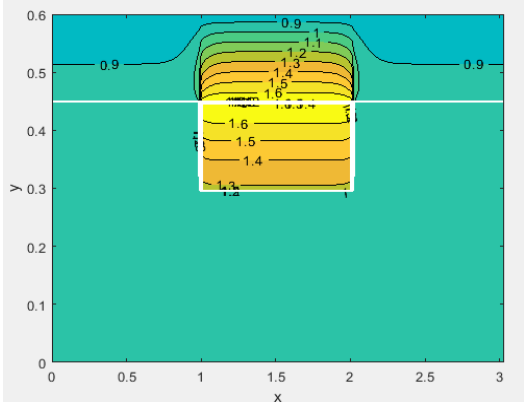

(a)

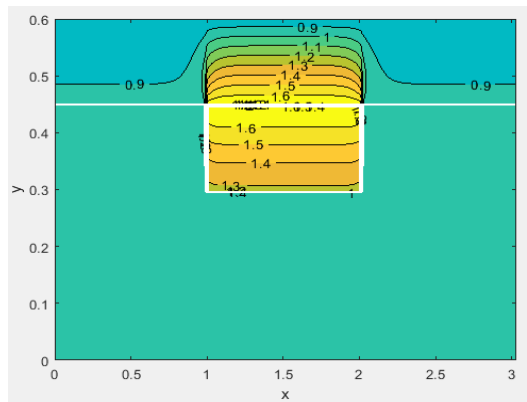

(b)

Fig. 2. (a) The temperature field in the "ice-cryobot-air" system at an ice temperature $263 \mathrm{~K}$; (b) The temperature field in the "ice-cryobot-air" system at an ice temperature $253 \mathrm{~K}$.

\section{Conclusion}

The article presents a mathematical model of the process of cryobot movement in the conditions of melting of massive ice structures. According to the results of mathematical modeling, it is established that the initial temperature of the cryobot can have a significant effect on the melting characteristics, while the average temperature of the cryobot with an increase in the cryobot temperature from $450 \mathrm{~K}$ to $500 \mathrm{~K}$ will increase its average bulk temperature at the time of immersion in ice at $383 \mathrm{~K}$. It was also found that a decrease in the initial temperature of ice from 263 to $253 \mathrm{~K}$ leads to an insignificant change in the characteristics of heat and mass transfer during the motion of the thermal barrier into a layer of massive ice structures. This is due to the fact that when the cryobot moves in the region of conjugation of the walls of the heat drill and ice, a water membrane is formed, the temperature of which is equal to the phase transition temperature of $273 \mathrm{~K}$. Such membrane creates a kind of barrier that prevents more intensive cooling of the cryobot.

\section{References}

1. N. I. Vasiliev, The results of drilling a 5G well at the Russian station "Vostok" and the study of ice cores $\mathbf{1 0}$ (2016)

2. N. I. Vasiliev, Rational technology of drilling wells in ice massifs using an electromechanical projectile on a cable (St. Petersburg, 2004) [in Russian]

3. P. G. Talalay, Nature 9 (2006)

4. P. Weiss, K. L. Yung, T. C. Ng, Planet. Space Sci. 56, 1280 (2008)

5. E. N. Chumachenko, D. Dunham, R. R. Nazirov, V. P. Kulagin, Vestnik of the Nizhny Novgorod University named after H. I. Lobakogo 6 (2011)

6. N. I. Vasiliev, Problems of the Arctic and Antarctic 76, 78 (2007) 
7. G. V. Parfenova, E. N. Chumachenko, Mathematics 13 (2010) [in Russian]

8. P. G. Talalay, Nature 1 (2002)

9. O. N. Korolyova, Dynamic adaptation in the multi-front problems of Stefan (Abstract, 2006)

10. J. Jonsson, J. Sundqvist, H. Nguyen, Acta Astronautica 79, 203 (2012)

11. L. Zelenyi, O. Korablev, M. Martynov, Advances in Space Research 48, 615 (2011)

12. S. V. Syrodoy, N. Y. Gutareva, R. I. Taburchinov, MATEC Web Conf. 72, 01109 (2016)

13. S. V. Syrodoy, N. Y. Gutareva, K. A. Bugaeva, MATEC Web Conf. 72, 01035 (2016) 